\title{
Scuffing load capacity calculation of worm gears
}

\author{
Philipp Roth $^{1}$ (D) $\cdot$ Michael Hein ${ }^{1}$ (i) $\cdot$ Karsten Stahl' $^{1}$
}

Received: 22 March 2021 / Accepted: 10 June 2021 / Published online: 6 July 2021

(c) The Author(s) 2021

\begin{abstract}
Worm gears with wheels of harder materials, such as cast iron or steel, are often prone to the damage type scuffing, which can cause a sudden and rapid failure of the gear box. Contact temperature is a suitable criterion to determine the scuffing safety for other types of gears. However, for worm gears, a scuffing load capacity calculation is not available at the moment. This paper presents a numerical temperature simulation for worm gears that considers transient multidimensional heat transfer and local frictional loading due to the contact. Based on the results of this simulation, this paper derives a simplified calculation of worm gear contact temperatures. The calculation only contains input parameters that are already part of current standards. Its result, the contact temperature of worm gears, can be used to rate the scuffing load capacity.
\end{abstract}

\section{Fresstragfähigkeitsberechnung von Schneckengetrieben}

\section{Zusammenfassung}

Schneckengetriebe mit Rädern aus härteren Werkstoffen, wie zum Beispiel Gusseisen oder Stahl, sind oft anfällig für die Schadensart Fressen, welche zu einem plötzlichen Ausfall des Getriebes führen kann. Für andere Verzahnungsarten hat sich die Kontakttemperatur als ein geeignetes Kriterium zur Bestimmung der Fresssicherheit bewährt. Für Schneckengetriebe ist derzeit jedoch eine verbreitete und genormte Berechnung zur Bestimmung der Fresssicherheit nicht verfügbar. In diesem Beitrag wird dementsprechend eine numerische Temperatursimulation für Schneckenräder vorgestellt, die den instationären und mehrdimensionalen Wärmetransport und die lokale Reibungsbelastung durch den Kontakt berücksichtigt. Basierend auf den Ergebnissen dieser Simulation wird in diesem Beitrag eine vereinfachte Berechnung der Kontakttemperaturen abgeleitet. Die Berechnung enthält nur Eingangsparameter, die bereits Bestandteil der aktuellen Normen sind. Das Ergebnis, die Kontakttemperatur von Schneckenverzahnungen, kann zur Bewertung der Fresstragfähigkeit verwendet werden.

Symbols

a Center distance $[\mathrm{mm}]$

$c \quad$ Specific heat capacity $[J /(k g K)]$

$i \quad$ Gear ratio [-]

$n \quad$ Rotational speed [revolutions/min]

$p_{H m} \quad$ Mean Hertzian contact stress $\left[N / \mathrm{m}^{2}\right]$

$\dot{q} \quad$ Heat flux $\left[\mathrm{W} / \mathrm{m}^{2}\right]$

$v_{g} \quad$ Sliding velocity $[\mathrm{m} / \mathrm{s}]$

Availability of data and material Not applicable

\section{Code availability Not applicable}

Philipp Roth

roth@fzg.mw.tum.de

1 Gear Research Centre (FZG), Technical University of Munich, Boltzmannstraße 15, 85748 Garching, Germany $v_{g m} \quad$ Sliding velocity at reference diameter $[\mathrm{m} / \mathrm{s}]$

$x \quad$ Coordinate in tooth height direction $[\mathrm{m}]$

$y \quad$ Coordinate in tooth width direction $[m]$

$A_{a c} \quad$ Active flank area $\left[\mathrm{m}^{3}\right]$

$A_{F l} \quad$ Flank surface area $\left[\mathrm{m}^{3}\right]$

$B_{T} \quad$ Thermal contact coefficient $\left[N^{2} /\left(m^{2} K^{2} s\right)\right]$

$P_{R} \quad$ Specific frictional power $\left[\mathrm{W} / \mathrm{m}^{2}\right]$

$R^{2} \quad$ Coefficient of determination [-]

$R_{T r} \quad$ Contact pattern ratio [\%]

$S_{B} \quad$ Scuffing safety factor [-]

$T \quad$ Torque $[\mathrm{Nm}]$

$X_{M} \quad$ Material coefficient [-]

$X_{T r} \quad$ Contact pattern coefficient [-]

$\sigma_{H} \quad$ Hertzian contact stress $\left[\mathrm{N} / \mathrm{m}^{2}\right]$

$\sigma_{H m} \quad$ Mean Hertzian contact stress $\left[\mathrm{N} / \mathrm{m}^{2}\right]$

$\vartheta_{B} \quad$ Contact temperature $\left[{ }^{\circ} \mathrm{C}\right]$

$\vartheta_{B P} \quad$ Scuffing temperature $\left[{ }^{\circ} \mathrm{C}\right]$ 


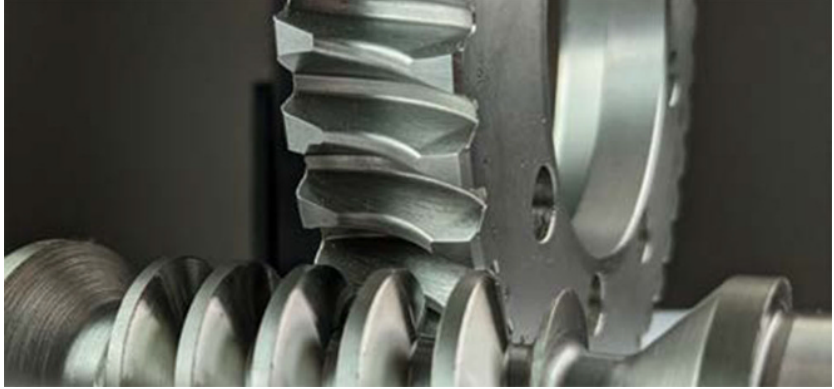

Fig. 1 Cast iron worm wheel (with corresponding worm in the foreground)

$\vartheta_{f l} \quad$ Flash temperature $\left[{ }^{\circ} \mathrm{C}\right]$

$\vartheta_{M} \quad$ Wheel bulk temperature $\left[{ }^{\circ} \mathrm{C}\right]$

$\vartheta_{\text {Oil }} \quad$ Oil injection temperature $\left[{ }^{\circ} \mathrm{C}\right]$

$\lambda \quad$ Thermal conductivity $[\mathrm{W} /(\mathrm{mK})]$

$\mu \quad$ Coefficient of friction [-]

$\mu_{z m} \quad$ Mean tooth coefficient of friction [-]

$\rho \quad$ Density $\left[\mathrm{kg} / \mathrm{m}^{3}\right]$

Indices

1 Worm

2 Worm wheel

\section{Introduction}

Worm gear drives realize high gear ratios in one stage and therefore are a compact way for a substantial speed reduction and torque increase. The worm is typically made of case-hardened steel, whereas the worm wheel is usually made of a relatively soft material, such as bronze. To allow the use of smaller and lighter drives with simultaneously less wear, the demand for worm wheels made of harder materials with greater strength, such as cast iron as shown in Fig. 1, is growing. Worm gear drives with worm wheels made of harder materials are already in use for mostly lowspeed applications, such as lifting devices or solar trackers for photovoltaic plants. Besides wear and pitting as common failure modes of worm gears, these material combinations are also prone to the failure mode scuffing at higher speeds. As scuffing damage can lead to rapid loss-of-drive of the gearbox, the accountable design of worm gears of such materials requires a reliable calculation method to determine the scuffing load capacity. As such a method is currently not available, the use of harder materials for worm wheels is not common for applications with higher speeds.

Hence, the objective of this paper is the development of a scuffing load capacity calculation method for worm gears. Two main requirements on the method are defined. First, the method needs to consider the specific conditions of worm gears in regards to their contact conditions. Second, the method should use input parameters, such as sliding velocity or mean Hertzian contact stress, that are already used and provided within current design practices, such as the worm gears standards ISO/TS 14521 [1] or DIN 3996 [2]. This allows for a practice-oriented application of the method within state-of-the-art design processes of worm gears.

To accomplish the objective, this paper presents a brief overview of the literature. Based thereof, it then describes a suitable approach and solution path to develop a scuffing load capacity calculation. The following main part describes the method itself and its foundation. Before the conclusion, the paper discusses the method and the potential for further research.

\section{Overview of the state of the art}

This chapter on the part of the state of the art that is relevant for the paper's objective briefly covers the topics of scuffing damage on gears in general, scuffing load capacity calculation of spur, helical, bevel and hypoid gears as well as contact temperature calculation of worm gears.

\subsection{Scuffing}

Scuffing of gears is understood to be the instantaneous welding of flank surfaces under the influence of the pressure and temperature conditions in the tooth contact. Due to the motion of the gears, the welded areas are teared apart and local damages with material transfer occur. Typically, ongoing load cycles further damage the flanks and lead to an accelerated failure of the gearbox as well as higher power losses and poorer dynamics [3, 4]. Fig. 2 displays typical scuffing marks on the flanks of a spur gear, a hypoid gear and a worm gear. The origin of scuffing damages is considered to be a metal-to-metal contact due to the absence of protecting layers $[3,5]$. These protecting layers are typically formed by the lubricant and its additives. Accordingly, and in contrast to fatigue damages, a single momentary overload can cause scuffing.

\subsection{Scuffing load capacity of spur, helical, bevel and hypoid gears}

To determine the scuffing load capacity of spur, helical, bevel and hypoid gears, current design standards, such as ISO/TS 6336-20 and -21 [8, 9] and ISO/TS 10300-20 [10], make use of contact temperature criteria. The calculation procedures of the standards include formulas for the contact temperature under consideration of the load conditions. To determine the scuffing safety factor, the thus calculated contact temperature of the considered gear box is then the divider for the scuffing temperature. The scuffing temper- 
Fig. 2 Typical scuffing marks on a spur gear (a) [6], a hypoid pinion (b) [7] and a worm gear $(\mathbf{c})$
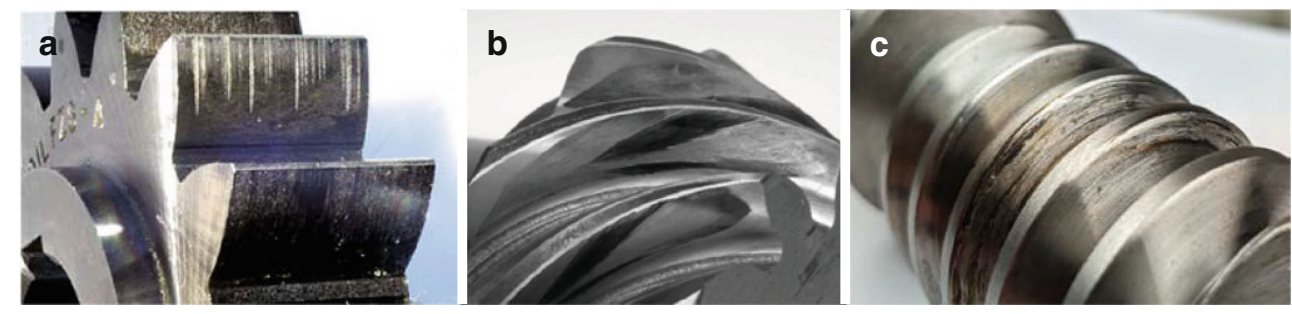

Fig. 3 Content and approach of this paper to develop a scuffing load capacity calculation method for worm gears

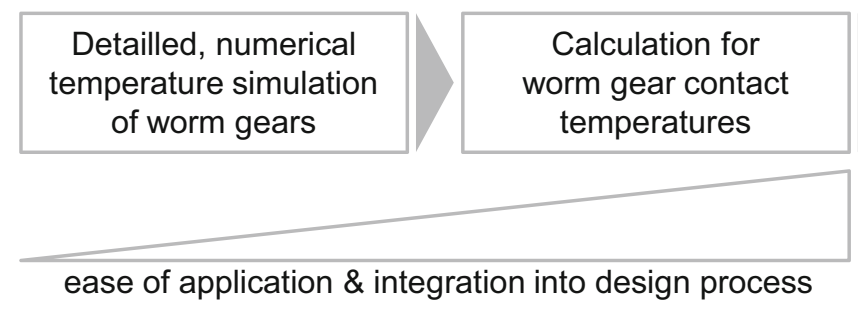

ease of application \& integration into design process
Scuffing load capacity

calculation method of worm gears

Permissible contact temperature for material/lubricant ature is a characteristic parameter of a material-lubricantsystem of a gear pair and is determined by gear tests. Generally, the approach of these standards to compare the contact temperature with a permissible temperature to rate the scuffing risk is a common practice [11-13].

\subsection{Temperature calculation of worm gears}

For worm gears, several works [14-17] that investigate worm wheels made from harder and stronger materials than bronze use an analogue approach to determine the scuffing load capacity. However, the basic calculations that these works use for the contact temperature are not fully applicable to worm gears. For example, Blok's calculation of the flash temperature $[18,19]$ considers only one-dimensional velocity conditions. While this is applicable to spur gears, worm gears are subject to more complex velocity conditions due to the rotational movement of the worm. Hence, these calculations of the flash temperature of worm gears show a sharp temperature peak in the middle of the flank, which is not plausible [20]. Accordingly, although the oil film temperature is calculated within the efficiency calculation [21], a standardized calculation method for the scuffing load capacity of worm gears is not yet included in DIN 3996 [2] or ISO/TS 14521 [1].

\subsection{Conclusion from the state of the art and problem formulation}

The overview of the state of the art shows that a gear's contact temperature is a suitable criterion to determine the scuffing risk of spur, helical, bevel and hypoid gears. Accordingly, design methods for these gear types successfully use the contact temperature in comparison with a permissible value to determine a scuffing safety factor.
However, the direct application of these methods to worm gears is not suitable due to different velocity conditions in the contact. Therefore, reliable and standardized calculation methods to determine the scuffing load capacity of worm gears are not available at the moment.

\section{Approach to develop a scuffing load capacity calculation of worm gears}

To fill the gap that is identified within the overview of the state of the art and to develop a method to determine the scuffing load capacity of worm gears, this paper derives a contact temperature calculation based on an extensive numerical temperature simulation of worm gears. According to the requirements, as stated in the introduction, a central part is to simplify the temperature simulation towards a practice-oriented calculation for the contact temperature of worm gears that can be included in the design process of ISO/TS 14521 [1] and DIN 3996 [2]. The method to determine the scuffing load capacity then uses the calculated contact temperature and compares it to a permissible contact temperature for a material-lubricant-combination. Fig. 3 summarizes this approach and therewith the content of the following main part of the paper. Determining permissible contact temperatures is not part of this paper.

\section{Temperature simulation of worm gears}

As the state of art shows, a temperature calculation of worm gears needs to consider the velocity conditions of a worm gear contact. For this, within the context of this research, an extensive numerical temperature simulation of the worm gear contact was developed. A more detailed description 


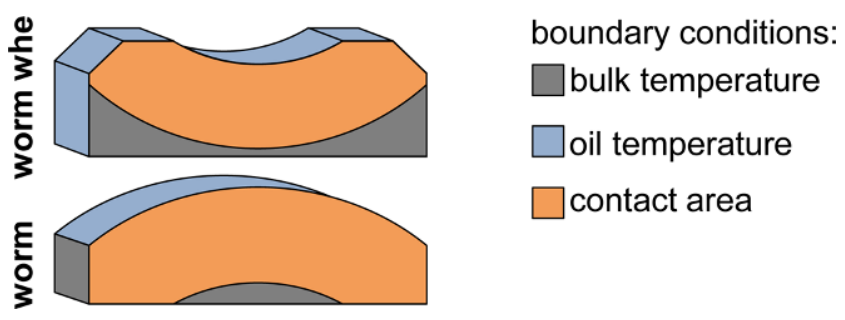

Fig. 4 Body geometry and applied boundary conditions within the temperature simulation

of the simulation and its theoretical validation are already published within [20]. Accordingly, the simulation is not described in detail within the scope of this paper. This chapter hence aims to give a brief overview of the simulation and its results.

\subsection{Geometry and boundary conditions}

The simulation considers an approximated geometry of a worm wheel tooth and a section of a worm tooth as shown in Fig. 4. The section of the worm has the width of a worm wheel tooth. The edges of the two bodies are loaded with boundary conditions. The boundary condition on the outside edges is the oil temperature (blue in Fig. 4). On the inside edges, it is the bulk temperature (gray in Fig. 4). The flank surface, where worm and worm wheel are in contact, is considered as the contact area (orange in Fig. 4).

The contact area is loaded with a frictional load that results from the contact of the worm with the worm wheel. The simulation considers the local loads and calculates the local heat flux strain $\dot{q}(x, y)$ based on the local coefficient of friction $\mu(x, y)$, the local Hertzian contact stress $\sigma_{H}(x, y)$ and the local sliding velocity $v_{g}(x, y)$ according to Eq. 1 .

$\dot{q}(x, y)=\mu(x, y) \cdot \sigma_{H}(x, y) \cdot v_{g}(x, y)$

The local Hertzian contact stresses and the local sliding velocities are calculated with the contact pattern calculation software SNETRA [22, 23], which can consider arbitrary geometries and multiple manufacturing settings. The local coefficients of friction are calculated iteratively depending on the local contact temperature and with a mixed friction approach according to [24].

\subsection{Solution of the model}

The numerical model then considers following components of heat transport:

- three-dimensional heat conduction
- three-dimensional convection (movement of the bodies relative to the contact area)

- transient course of the contact line.

The bodies and the boundary conditions are discretized by a finite difference scheme. This model is then solved for the transient temperatures of the bodies with an adapted approach according to [25] and by using a successive overrelaxation method.

\subsection{Results of the temperature simulation}

The simulation determines the transient course of the surface or rather contact temperatures in the contact area and of the temperatures below the surface. This allows for a detailed analysis of the temperature behavior of worm gear teeth during a meshing cycle under consideration of the loaded contact pattern and for arbitrary geometries and manufacturing settings. Fig. 5 shows the results of an exemplary calculation for a worm gear set with a center distance of $a=100 \mathrm{~mm}$ and a gear ratio of $i=20.5$ that is loaded with a speed of $n_{1}=1500$ revolutions $/ \mathrm{min}$ at the worm shaft and a torque of $T_{2}=1000 \mathrm{Nm}$ at the worm wheel shaft. A full contact pattern is considered. The mean Hertzian contact stress is about $\sigma_{H m}=520 \mathrm{~N} / \mathrm{mm}^{2}$ and the sliding velocity at the reference diameter is about $v_{g m}=3 \mathrm{~m} / \mathrm{s}$. Displayed are the maximum contact temperatures at each spot of the flank that occurred during one meshing cycle. Hence, it shows the highest temperature that each spot of the flank experiences. The overall highest temperature in the exemplary calculation is about $270^{\circ} \mathrm{C}$.

If one point in time of the meshing cycle was observed, the temperature rise along one line of contact would be visible. However, to determine the overall maximum temperature, the evaluation of the calculation results as in Fig. 5 is convenient. According to the flash temperature concept of Blok [26], the overall maximum temperature is a suitable parameter to determine the scuffing risk. The numerical temperature simulation allows to calculate this parameter for arbitrary worm gear geometries and operating conditions.

\section{Contact temperature calculation}

While the numerical temperature simulation is a suitable tool to determine the contact temperature of worm gears, it is lacking ease of handling and requires long calculating times. This makes it an expert software and suitable mainly for use in research. It therefore is not optimal for application by users within the practical design process. Accordingly, this chapter has the objective to derive a calculation that is easy to handle and can be integrated into the 
Fig. 5 Local maxima of contact temperatures during one meshing cycle of an exemplary calculation with the numerical temperature simulation

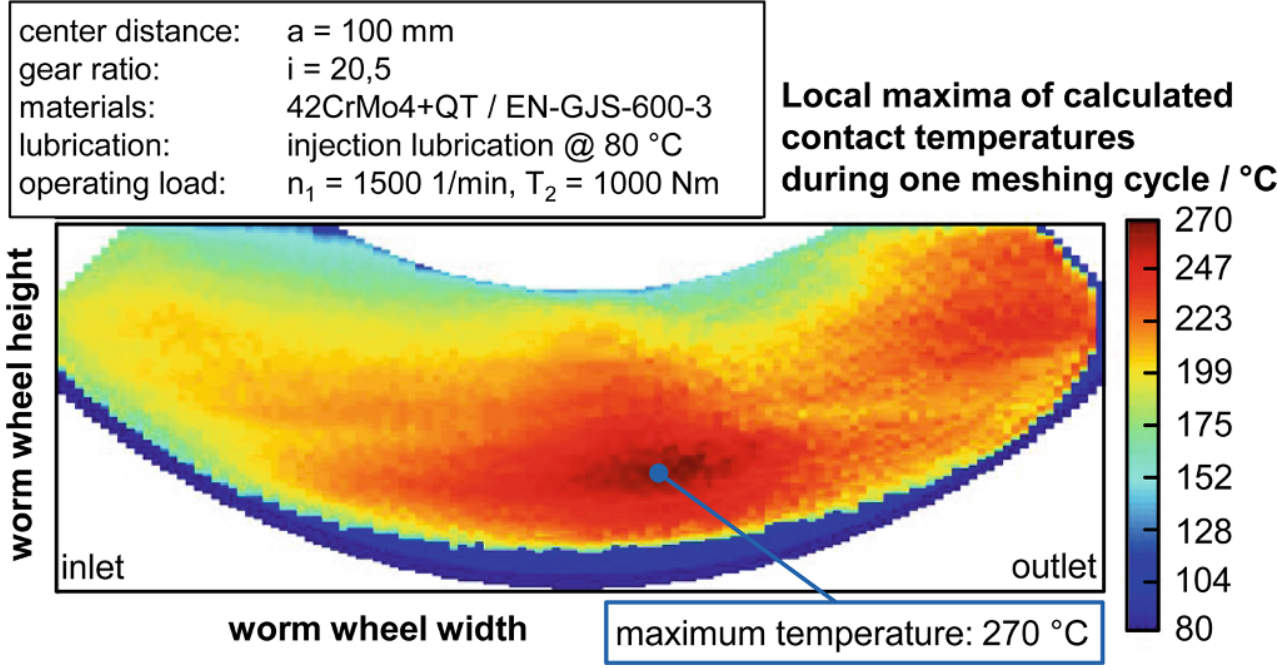

Fig. 6 Correlation between specific frictional power and flash temperature (for numerical simulation and the thereof derived Eq. 3)

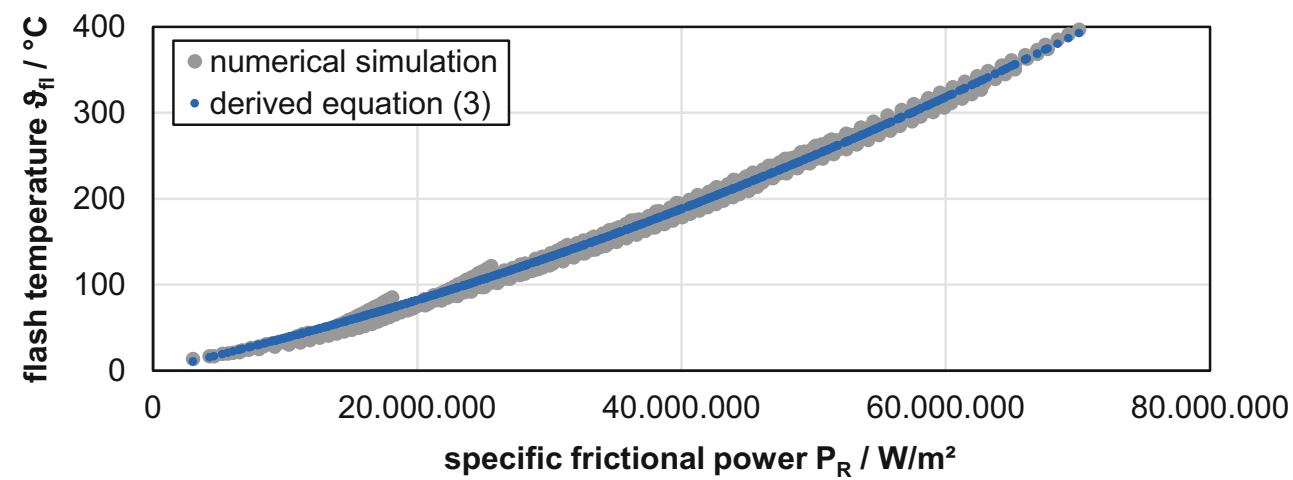

current standards ISO/TS 14521 [1] and DIN 3996 [2] for the load carrying capacity calculation of worm gears. For this, a regression analysis is conducted to derive simplified formulas for the contact temperature based on the results of the numerical temperature simulation. This chapter first describes the approach of the regression analysis and then presents the thereof derived formulas.

\subsection{Regression analysis}

To determine the main influencing factors on the contact temperature, several parameters are varied in about 800 simulations. The variation includes following parameters:

- operating conditions (torque and rotational speed) ( $n_{1}=100 \ldots 4000$ revolutions $/ \mathrm{min}, T_{2}=100 \ldots 1500 \mathrm{Nm}$ )

- sizes $(a=65 \ldots 160 \mathrm{~mm})$

- contact pattern ratios and contact pattern positions $\left(R_{T r}=25 \ldots 100 \%\right)$

- materials (wheel: EN-GJS-600-3 \& CuSn12Ni2, worm: 42CrMo4 \& $16 \mathrm{MnCr} 5)$
- oil and bulk temperatures $\left(\vartheta_{\text {Oil }}=60 \ldots 120^{\circ} \mathrm{C}, \vartheta_{M}=60 \ldots 140^{\circ} \mathrm{C}\right)$.

Based on the variational calculations of the operating conditions, three main influencing factors on the maximum contact temperature can be identified:

- sliding velocity at reference diameter

- mean Hertzian contact stress

- mean tooth coefficient of friction.

These are also the mean values of the contact parameters that determine the local heat flux strain in the numerical temperature simulation according to Eq. 1. These three parameters can be summarized within the specific frictional power $P_{R}$ as is later defined by Eq. 4. Fig. 6 shows the maximum contact temperature rise, or rather the flash temperature, over the specific frictional power. The grey entries show the results obtained by the temperature simulation. The blue entries are the results of a regression analysis of the correlation between the specific frictional power and the flash temperature as calculated with the temperature simulation. The underlying formula is later shown as Eq. 3. The 


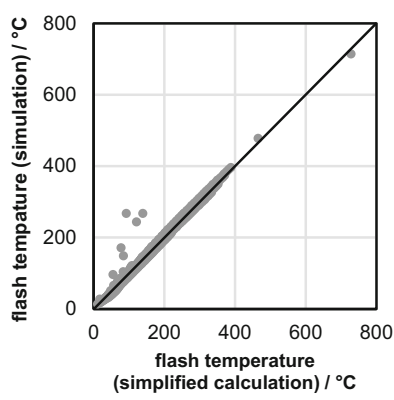

Fig. 7 Comparison of the results of the simplified calculation with the results of the simulation

coefficient of determination of the results of Eq. 3 and the simulation results is $R^{2} \approx 0.98$.

Further parameters that influence the contact temperature are the contact pattern ratio and thermal material properties. The temperature simulation allows to determine the influence of these parameters. Accordingly, the contact pattern coefficient $X_{T R}$ and the material coefficient $X_{M}$ are defined to consider these influences. The formulas to calculate the flash temperature, which are presented in the next section, use these coefficients.

Fig. 7 shows the results of the derived formulas in comparison to the results of the temperature simulation. Each entry point depicts one variational calculation. For each variation, the temperature simulation and the simplified calculation provide a result for the flash temperature. Points that lie on the diagram diagonal are identical for both calculations. The aim is that the results of the simplified calculation match the results of the more extensive temperature simulation.

As Fig. 7 shows, the simplified temperature calculation, which was newly developed within the research for this paper, reproduces the behavior of the temperature simulation very well. Single results deviate due to very small contact patterns, of which the local loads are overestimated by the underlying loaded tooth contact analysis of the simulation. Thus, the simplified calculation can be used as a practical and user-friendly substitution of the temperature simulation. It therewith provides a calculation to determine the contact temperature of worm gears within the design process.

\subsection{Derived formulas for contact temperature calculation}

Based on the presented regression analysis, formulas are derived within in this paper. These new formulas compose a novel calculation to determine the contact temperature of worm gears. The following section describes this calculation.

The contact temperature $\vartheta_{B}$ consists, according to Eq. 2, of the wheel bulk temperature $\vartheta_{M}$ and the temperature rise due to the frictional contact, the flash temperature $\vartheta_{f l}$.

$\vartheta_{B}=\vartheta_{M}+\vartheta_{f l}$

The wheel bulk temperature can, for example, be calculated with DIN 3996 [2]. As it depends strongly on the heat dissipation properties of the gear box system [27, 28], the wheel bulk temperature might also be measured on the actual gear box for better accuracy. The flash temperature is determined with Eq. 3 that contains the specific frictional power $P_{R}$ and the material coefficient $X_{M}$.

$$
\begin{aligned}
\vartheta_{f l}= & \left(0.03 \cdot\left(\frac{P_{R}}{10^{6} \cdot\left[\frac{W}{\left(m^{2}{ }^{\circ}\right)}\right]}\right)^{2}\right. \\
& \left.+3.5 \cdot \frac{P_{R}}{10^{6} \cdot\left[\frac{W}{\left(m^{2}{ }^{\circ} \mathrm{C}\right)}\right]}\right) \cdot X_{M}
\end{aligned}
$$

As Eq. 4 shows, the specific frictional power is a product of the mean tooth coefficient of friction $\mu_{z m}$, the mean Hertzian contact stress $\sigma_{H m}$ and the sliding velocity at the reference diameter $v_{g m}$.

$P_{R}=\mu_{z m} \cdot\left(\sigma_{H m} \cdot X_{T r}\right) \cdot v_{g m}^{0.8}$

These three parameters are results of calculations such as DIN 3996 [2]. They can also be determined by more extensive simulations, such as loaded tooth contact analyses. The contact pattern coefficient $X_{T r}$ scales the contact stress.

The material coefficient considers the influence of material properties on the heat transfer out of the contact. Equation 6 describes the correlation of the material coefficient with the thermal contact coefficient for the worm $B_{T, 1}$ and the worm wheel $B_{T, 2}$.

$$
\begin{aligned}
X_{M}= & 0.5 \cdot\left(\left(\frac{1.5 \cdot 10^{-14} \cdot\left[N^{2} /\left(m^{2} K^{2} s\right)\right]}{B_{T, 1}}\right)^{\frac{2}{3}}\right. \\
& \left.+\left(\frac{1.3 \cdot 10^{-14} \cdot\left[N^{2} /\left(m^{2} K^{2} s\right)\right]}{B_{T, 2}}\right)^{\frac{2}{3}}\right)
\end{aligned}
$$


According to Eq. 6, the respective thermal contact coefficient consists of three common material properties: thermal conductivity $\lambda$, specific heat capacity $c$ and density $\rho$.

$B_{T, i}=\lambda_{i} \cdot c_{i} \cdot \rho_{i}$

The contact pattern coefficient describes the influence of a partial contact pattern on the mean Hertzian contact stress, which is typically determined for a full contact pattern. According to [29] and Eq. 7, the contact pattern coefficient depends on the contact pattern ratio $R_{T r}$. Further publications on this coefficient are currently in preparation.

$$
X_{T r}=\left\{\begin{array}{c}
2-0.01 \cdot\left[\frac{1}{\%}\right] \cdot R_{T r} \quad \text { for } R_{T r} \geq 40 \% \\
1.6+0.001 \cdot\left(40 \%-R_{T r}\right)^{2} \cdot\left[\frac{1}{\%^{2}}\right] \text { for } R_{T r}<40 \%
\end{array}\right.
$$

As contained in Eq. 8, the contact pattern ratio describes the proportion of the active tooth flank $A_{a c}$, where a contact takes place, and the total flank surface area $A_{F l}$. It can be determined by numerical calculation $[22,23]$ or visual inspection of the actual gear box.

$R_{T r}=\frac{A_{a c}}{A_{F l}} \cdot 100 \cdot[\%]$

These formulas form a calculation to determine the contact temperature of worm gears. The calculation fulfills the requirements as initially stated in the introduction. With it being based on the temperature simulation, it considers the detailed velocity and contact conditions of worm gears. It only uses input parameters that are the result of existing design standards for worm gears (sliding velocity at reference diameter, mean Hertzian contact stress, mean tooth coefficient of friction) or can be easily obtained (contact ratio, material properties).

\section{Scuffing load capacity calculation}

To determine the scuffing load capacity of a worm gear, Eq. 9 proposes a scuffing safety factor $S_{B}$. This factor weights a permissible contact temperature, which is usually named the scuffing temperature $\vartheta_{B P}$, with the contact temperature of the regarded gear $\vartheta_{B}$. This is based on flash temperature criterions for spur, helical, bevel and hypoid gears as known from ISO/TS 6336-20 [8] and ISO/TS 10300-20 [10].

$S_{B}=\frac{\vartheta_{B P}}{\vartheta_{B}}$

For worm gears, the presented calculation allows to calculate the contact temperature. The scuffing temperature is a material- and lubricant-depended parameter that requires experimental determination using a scuffing test, for which the contact temperatures are recalculated by help of the presented formulas. The scuffing temperature describes at which calculated contact temperature scuffing damages occur within the test conditions. For spur gears, such tests are standardized in, for example, DIN 51354-2 [30] or Ryder [31]. The definition of such a test for worm gears is not within the scope of this paper and subject of further research. This is also the case for defining necessary safety factor values for a reliable, scuffing-free operation of worm gears.

\section{Discussion}

This chapter discusses the presented results and describes possibilities for further research and improvement.

Rating the scuffing load capacity of gears with a temperature criterion requires two elements: a calculation for contact temperatures and an experimental test procedure to determine material- and lubricant-dependent contact temperatures at which scuffing occurs. The latter is, as mentioned in the previous chapter, not subject of this paper. Further research should aim to develop a scuffing test for worm gears.

The other necessary element, a contact temperature calculation, is provided by this paper. The introduction stated two requirements on the calculation: it needs to consider the specific contact conditions of worm gears and needs to be integrable into current standards. Both requirements are fulfilled by the presented calculation method. A previous work [20] shows with a theoretical validation that the underlying numerical temperature simulation considers the velocity conditions in the worm gear contact more precisely than previous calculations. However, an experimental validation of the underlying simulation could further confirm the results. For this, experimental temperature measurements are already planned. Regarding the second requirement, which is the integrability of the simplified contact temperature calculation into existing standards, the presented calculation only uses input parameters that are already part of ISO/TS 14521 [1] and DIN 3996 [2]. These parameters are, for example, the mean Hertzian contact stress $p_{H m}$ or the mean tooth coefficient of friction $\mu_{z m}$. Therefore, the contact temperature calculation could be integrated into the existing standards with ease.

It is yet to be investigated how well the presented method to determine the scuffing load capacity describes the damage behavior of actual worm gear boxes. Influencing factors that can lead to deviations between calculation and operation are, for example, run-in effects and surface structures. Their influence and whether it can be included in the calculations should be subject of further research. Within 
these investigations, the suitability of an integral temperature method [32] for worm gears could be reviewed as well. To calculate the integral temperature for worm gears, an approach that is analogue to this paper and also based on the presented numerical temperature simulation can be used.

Overall, the objective of the paper could be realized and the presented novel contact temperature calculation fills the current gap in the state of the art. In addition to this calculational framework, experimental investigations of scuffing of worm gears are necessary within further research.

\section{Summary \& conclusion}

Contact temperature, as this paper shows in the state of the art, is the most commonly used criterion to determine the scuffing load capacity of gears. However, for worm gears, no calculation for the contact temperature is available in general use. To fill this gap, this paper aims to develop a contact temperature calculation for worm gears as a basis for a scuffing load capacity calculation method. For this, the paper uses an extensive numerical contact temperature calculation that considers the specific contact conditions of worm gears. It solves the three-dimensional heat transport within the tooth of the worm and the tooth of the worm wheel. The heat source is the transient frictional contact of the gears. This temperature simulation provides the maximum temperatures that occur at each point of the flank surfaces during one meshing cycle. Using the simulation to vary geometries, load conditions and materials allows to identify influencing factors on the contact temperature. Based on these influencing factors and the results of the simulation, a novel simplified calculation for the contact temperature of worm gears is derived. This calculation uses input parameters that are already part of current standards. It is therefore integrable into the current design process of worm gears. The calculation of the contact temperatures can then be used within a method to rate the scuffing load capacity of worm gears. For this, it is necessary to develop a test procedure to experimentally determine the scuffing temperature of worm gears within further research. The scuffing temperature is the temperature at which scuffing occurs for a certain material- and lubricant-combination. Such a design method for the scuffing load capacity will eventually enable the accountable development of worm gears with wheels made of harder materials.

Funding The presented results are based on the research project FVA 799 I/IGF no. $19564 \mathrm{~N}$ undertaken by the Research Association for Drive Technology e. V. (FVA) and supported partly by the FVA and through the German Federation of Industrial Research Associations e. V. (AiF) in the framework of the Industrial Collective Research (IGF) program by the Federal Ministry for Economic Affairs and En- ergy (BMWi) based on a decision taken by the German Bundestag. The authors would like to thank for the sponsorship and support received from the FVA and the AiF as well as from the members of the project committee.

Funding Open Access funding enabled and organized by Projekt DEAL.

Conflict of interest P. Roth, M. Hein and K. Stahl declare that they have no competing interests.

Open Access This article is licensed under a Creative Commons Attribution 4.0 International License, which permits use, sharing, adaptation, distribution and reproduction in any medium or format, as long as you give appropriate credit to the original author(s) and the source, provide a link to the Creative Commons licence, and indicate if changes were made. The images or other third party material in this article are included in the article's Creative Commons licence, unless indicated otherwise in a credit line to the material. If material is not included in the article's Creative Commons licence and your intended use is not permitted by statutory regulation or exceeds the permitted use, you will need to obtain permission directly from the copyright holder. To view a copy of this licence, visit http://creativecommons.org/licenses/by/4. $0 /$.

\section{References}

1. ISO/TS 14521:2020-04 (2020) Gears-Calculation of load capacity of worm gears

2. DIN 3996:2019-09 (2019) Calculation of load capacity of cylindrical worm gear pairs with rectangular crossing axes

3. Höhn B-R, Michaelis K, Collenberg H, Schlenk L (2001) Effect of temperature on the scuffing load capacity of EP gear lubricants. Tribotest 7(4):317-332. https://doi.org/10.1002/tt.3020070405

4. Niemann G, Winter H (2003) Getriebe allgemein, Zahnradgetriebe - Grundlagen, Stirnradgetriebe, 2nd edn. Maschinenelemente, vol 2. Springer, Berlin, Heidelberg, New York

5. Enthoven J, Spikes HA (1996) Infrared and visual study of the mechanisms of scuffing. Tribol Trans 39(2):441-447. https://doi. org/10.1080/10402009608983550

6. Sagraloff N, Winkler K-J, Tobie T, Stahl K, Folland C, Asam T (2021) Investigations on the scuffing and wear characteristic performance of an oil free water-based lubricant for gear applications. Lubricants 9(3):1-19. https://doi.org/10.3390/lubricants9030024

7. Reimann T, Stemplinger J-P, Stahl K (2015) Der Fresstest A/44/Cr - eine Methode zur Prüfung des Fress- und Verschleißverhaltens von Hypoidölen. Tribol Schmierungstech 62(2):46-53

8. ISO/TS 6336-20:2017 (2017) Calculation of load capacity of spur and helical gears-Part 20: Calculation of scuffing load capacity (also applicable to bevel and hypoid gears)_Flash temperature method

9. ISO/TS 6336-21:2017 (2017) Calculation of load capacity of spur and helical gears-Part 21: Calculation of scuffing load capacity (also applicable to bevel and hypoid gears) - Integral temperature method

10. ISO/TS 10300-20:2021-03 (2021) Calculation of load capacity of bevel gears-Part 20: Calculation of scuffing load capacity; Flash temperature method

11. Bowman WF, Stachowiak GW (1996) A review of scuffing models. Tribol Lett 2:113-131. https://doi.org/10.1007/BF00160970

12. Li S, Kahraman A (2021) A scuffing model for spur gear contacts. Mech Mach Theory 156:104161. https://doi.org/10.1016/j. mechmachtheory.2020.104161

13. Pellkofer J, Boiadjiev I, Kadach D, Klein M, Stahl K (2019) New calculation method for the scuffing load-carrying capacity 
of bevel and hypoid gears. Proc Inst Mech Eng C J Mech Eng Sci 233(21-22):7328-7337. https://doi.org/10.1177/0954406219843954

14. Lange N (2000) Hoch fresstragfähige Schneckengetriebe mit Rädern aus Sphäroguss. Dissertation, Technische Universität München

15. Steingröver K (1993) Untersuchungen zu Verschleiß, Verlustgrad und Fressen bei Zylinder-Schneckengetrieben. Dissertation, Technische Universität München

16. Pfäfflin B (1998) Schneckengetriebe zur Leistungsübertragung mit Radsätzen aus einsatzgehärtetem Stahl. Dissertation, Universität Stuttgart

17. Sternberg M (1996) Untersuchungen zum Betriebsverhalten von Schneckengetrieben mit Radsätzen aus einsatzgehärtetem Stahl. Dissertation, Universität Stuttgart

18. Blok H (1937) Theoretical study of temperature rise at surfaces of actual contact under oiliness lubricating conditions. Proceedings of the general discussion on lubrication and lubricants, vol 2, pp 222-235

19. Blok H (1937) Les Temperatures du Surface das des Conditions de Graissage sous Extreme Pression. In: 2nd World Petroleum Congress Paris, pp 471-486

20. Roth P, Sigmund W, Kadach D, Born S, Stahl K (2017) A numerical approach to the calculation of the surface temperature distribution of worm gears. In: Proceedings of the ASME International Design Engineering Technical Conferences and Computers and Information in Engineering Conference (IDETC/CIE) - ASME International Power Transmission and Gearing Conference (PTG) 10 https://doi.org/10.1115/DETC2017-67049

21. Oehler M, Magyar B, Sauer B (2017) Ein neuer, normungsfähiger Berechnungsansatz für den Wirkungsgrad von Schneckengetrieben. Forsch Ingenieurwes 81:145-151. https://doi.org/10.1007/s10010017-0225-1

22. Höhn B-R, Steingröver K, Lutz M (2003) Determination and optimization of the contact pattern of worm gears. In: Gear Technology March/April 2003, pp 12-17
23. Roth P, Kadach D, Stahl K (2018) FVA-No. 320 VII-Issue 1301-SNESYS V final report-Anwendungsorientierte Kombination von Verschleiß- und Grübchensimulation in SNETRA. Forschungsvereinigung Antriebstechnik e. V, Frankfurt a.M.

24. Doleschel A (2002) Wirkungsgradberechnung von Zahnradgetrieben in Abhängigkeit vom Schmierstoff. Dissertation, Technische Hochschule München

25. Winkler H (1986) Berechnung der Temperatur- und Spannungsfelder von Gleit-Wälzpaarungen. Dissertation, Technische Universität München

26. Blok H (1963) The flash temperature concept. Wear 6(6):483-494. https://doi.org/10.1016/0043-1648(63)90283-7

27. Paschold C, Sedlmair M, Lohner T, Stahl K (2020) Efficiency and heat balance calculation of worm gears. Forsch Ingenieurwes 84:115-125. https://doi.org/10.1007/s10010-019-00390-1

28. Norgauer P, Grunewald L, Priester L, Heilemann J, Hein M, Stahl K (2020) Experimentelle Ermittlung der Ölströmung in tauchgeschmierten Schneckengetrieben. Forsch Ingenieurwes 84:141-150. https://doi.org/10.1007/s10010-020-00393-3

29. Roth P, Hein M, Stahl K (2021) FVA-No. 320 VIII-SNESYS VI status report-Weiterentwicklung des Programmsystems SNESYS zur Berechnung von Schneckengetrieben. Forschungsvereinigung Antriebstechnik e. V., Frankfurt a.M.

30. DIN 51354-2:1990-04 (1990) Testing of lubricants-FZG gear test rig - method $\mathrm{A} / 8,3 / 90$ for lubricating oils

31. FED-STD-791D (2007) Method 6508.2—Load Carrying Capacity of Lubricating Oils (Ryder Gear Machine)

32. Michaelis K (1987) Die Integraltemperatur zur Beurteilung der Fresstragfähigkeit von Stirnradgetrieben. Dissertation, Technische Universität München 